\title{
Modeling the impact of tuberculosis interventions on epidemiologic outcomes and health system costs
}

\author{
Olivia Oxlade ${ }^{1}$, Amy Piatek ${ }^{3}$, Cheri Vincent ${ }^{3}$ and Dick Menzies ${ }^{1,2^{*}}$
}

\begin{abstract}
Background: Tuberculosis (TB) programs must invest in a variety of TB specific activities in order to reach ambitious global targets. Uncertainty exists surrounding the potential impact of each of these activities. The objective of our study was to model different interventions and quantify their impact on epidemiologic outcomes and costs from the health system perspective.

Methods: Decision analysis was used to define the TB patient trajectory within the health system of three different countries. We considered up to seven different interventions that could affect either the natural history of TB, or patient trajectories within the health system. The expected impact of interventions were derived from published studies where possible. Epidemiologic outcomes and associated health system costs were projected for each scenario.

Results: With no specific intervention, TB related death rates are high and less than $10 \%$ of the population starts on correct treatment. Interventions that either prevent cases or affect all patients with TB disease early in their trajectory are expected to have the biggest impact, regardless of underlying epidemiologic characteristics of the setting. In settings with a private sector, improving diagnosis and appropriate treatment across all sectors is expected to have a major impact on outcomes.

Conclusion: In all settings, the greatest benefit will come from early diagnosis of all forms of TB. Once this has been achieved more specific interventions, such as those targeting HIV, drug resistance or the private sector can be integrated to increase impact.
\end{abstract}

Keywords: Tuberculosis, Epidemiology, Decision analysis, Infectious disease modelling, Public health interventions

\section{Background}

Beginning in the mid-1980s, tuberculosis (TB) incidence dramatically increased globally, mostly attributed to urbanization in low and middle income countries (LMIC) and the HIV/AIDS epidemic. The emergence of multi drug-resistant TB (MDR-TB) has further contributed to the challenges of TB diagnosis and treatment. In response to the TB crisis, the World Health Organization (WHO) declared TB a global emergency in 1993. The Stop TB Partnership and the Global TB Drug Facility (GDF) $[1,2]$ were created to help provide more support to

\footnotetext{
*Correspondence: dick.menzies@mcgill.ca

'McGill University and the McGill International TB Centre, Montreal, Canada ${ }^{2}$ Montreal Chest Institute, 3650 St. Urbain St, Montréal H2X 2P4, PQ, Canada Full list of author information is available at the end of the article
}

countries, especially to National TB Programs (NTP), and by the late 1990s the United States Government started to provide funding to support NTP activities.

In 2006, WHO and the Stop TB Partnership launched an ambitious global plan to reach the Millennium Development Goal (MDG) targets of a 50\% reduction in TB prevalence and mortality [3]. The Stop TB Strategy provided the operational plan to reach these targets and included a comprehensive approach to improve TB case detection and treatment outcomes [1]. Increases in funding by external donor agencies and some national governments have led to the implementation of the global plan and progress toward the MDGs [4].

As a result of these efforts, TB prevalence and mortality have declined. However, in 2013 there were 9.0 million 
new cases of TB and 1.5 million deaths from the disease [3]. A new post-2015 plan has been developed by global partners calling for increased investment in both evidencebased and innovative strategies to achieve $90 \%$ reduction in cases and zero TB deaths $[5,6]$. Given the uncertainty on how to effectively and efficiently achieve these ambitious objectives, we have modeled the potential impact of different TB interventions on long term epidemiologic outcomes and health system costs.

\section{Methods}

\section{General approach to modeling}

We used decision analysis to compare the impact on epidemiologic outcomes, and health system costs of different interventions to strengthen TB programs in LMICs that could affect either the natural history or patient trajectories of TB disease. Pathogenetic and epidemiologic inputs, as well as the impact of interventions, were derived from the published literature. The model predicted the number of new primary and associated secondary TB cases, TB mortality, and TB related national health system costs over 20 years (2001-2020).

\section{Population}

Three countries (Indonesia, Kazakhstan, and Mozambique) with different initial incidence of active disease, prevalence of drug resistance, HIV co-infection and health provider landscape were considered. Indonesia was considered representative of high TB burden, but low drug resistance and low HIV burden, with a private sector. Kazakhstan was considered representative of high TB burden, with high drug resistance, but low HIV burden and no private sector and Mozambique was considered high TB burden, with low drug resistance, and high HIV burden and with no private sector.

For each country-specific epidemiologic data relating to $\mathrm{TB}$ incidence, treatment outcomes, drug resistance and HIV co-infection were taken from published sources [7-9]. Drug resistance was categorized as multi drug resistant (MDR-TB) - which included any form of Rifampin resistance or drug sensitive (DS-TB). DS-TB included all cases that were not classified as MDR-TB, including those that were mono- and poly-drug resistant.

\section{Overview of decision analysis model}

A decision analysis model was constructed based on a conceptual framework developed to represent the natural history of $\mathrm{TB}$ and opportunities for intervention (see Additional file 1: Figure S1 for more detail). The population cohort was initially divided into those with and without TB infection. The population was then further stratified by HIV infection status as well as drug resistance.
Each year, those who were uninfected with TB could stay uninfected or acquire infection. Those with TB infection could remain without disease (with latent infection), or develop active disease in each year; this rate was higher in the first two years after infection. As summarized in Additional file 1: Figure S2 in the supplement, individuals with active TB could then begin seeking care. Individuals could either seek care without any delay, or after a delay. Depending on the setting, patients could seek care at different types of health facilities (in up to 3 sectors -public, informal (such as natural healers), or private). In each sector a correct or an incorrect diagnostic test could be ordered. If an incorrect test was ordered an individual would not be diagnosed, and would remain untreated. If a correct diagnostic test was ordered, this test could be ordered immediately, or with a delay. Some patients will not continue through the process to receive a diagnostic result. If diagnosed, the treatment prescribed could be correct (i.e. an NTP- or WHO-recommended regimen), or incorrect. If incorrect it was assumed the therapy was ineffective and cure rates were lower than those specified for recommended therapy. TB treatment could be initiated immediately, or after a delay. For those with MDRTB disease, patients could receive a drug susceptibility test (DST) and be prescribed appropriate treatment, or not receive a DST and be given treatment for DS-TB (considered ineffective). Of those who started on correct therapy some completed treatment and were cured, others lost to follow-up, were not cured, relapsed or died. Active cases that received no treatment or inadequate treatment were considered to continue to transmit $M$. tuberculosis to the community until they either cured spontaneously or died from TB. This contributed to the number of secondary active cases generated during the simulation. Cases that incurred any delay were considered to continue to transmit the bacilli and could die during the period of delay. Specific probabilities of all of these events occurring are described below.

\section{Pre-intervention inputs \\ Epidemiologic inputs}

Epidemiologic inputs (initial annual risk of TB infection, HIV and drug resistance rates) varied by country. Pathogenetic inputs and outcomes for undiagnosed/untreated cases varied by HIV status. Input values, taken from published studies, are summarized in the supplemental appendix (Additional file 1: Table S1).

\section{Diagnostic and treatment related inputs}

Pre-intervention diagnostic variables are summarized in Additional file 1: Table S2 and S3 in the supplemental appendix. Most inputs varied by sector (where relevant), but not by country, and were identified through an 
extensive systematic review of published studies of the effect of programme interventions on TB diagnostic and treatment outcomes. Since published estimates of patient, diagnostic, and treatment delays are generally average times in days or months, these average delays were converted into the probability of a one year delay. For example, an average delay of 30 days was considered equivalent to a one year delay for $8 \%$ of those with active TB seeking care, and no delay for the remaining $92 \%$. TB treatment outcomes varied by country, type of underlying drug resistance, HIV status, and if DST was performed (Additional file 1: Table S3 in the supplemental appendix). In the pre-intervention scenario, HIV infected individuals were assumed to have no access to anti-retroviral therapy (ART).

\section{Health system costs}

All costs are summarized in Additional file 1: Table S4 in the supplemental appendix. Per item health system costs included those associated with TB diagnosis and treatment. TB treatment costs included drug costs, costs associated with DOT visits, and monthly medical follow up costs. Treatment costs were calculated separately for DS cases and MDR cases to reflect the higher drug costs and much longer duration of follow up. For DS or MDR cases that were lost to follow up, $50 \%$ of the full treatment cost was attributed. Medical visit costs (ie. medical follow up and treatment visit costs) varied by country $[10,11]$ and were adjusted using World Bank data [12]. Diagnostic test, DST and drug costs were priced using WHO CHOICE data [13] and other international suppliers [2]. Costs associated with the implementation of the interventions were not included, because none of the published studies providing information on the impact of interventions considered provided corresponding cost estimates. All costs are in 2010 US Dollars.

\section{Interventions}

Using the conceptual framework described above (see Additional file 1: Figure S1 for more detail), TB related interventions were matched to the stages of a TB patient's natural history and trajectory through the health system. For example, investment in laboratory strengthening was considered an intervention that would affect diagnosis during the "diseased" stage of the framework. Interventions were considered if they had been supported by external funding agencies in the past and were prioritized during periods of NTP strengthening or expansion since 2000. Interventions were grouped into one of seven categories: 1) Community education, 2) Expansion of TB diagnostic network (DOTS expansion for Diagnosis), 3) Education and supervision of health care workers about correct treatment regimens (DOTS expansion for treatment), 4) Other DOTS expansion interventions not specifically related to diagnosis or treatment (Non Specific DOTS expansion- NTP strengthening), 5) Private sector interventions, 6) Expanded access to DST and reduced loss to follow up during treatment - for MDR (MDR-TB related Interventions), 7) Expanded access to ART for HIV co-infection (HIV/ART Therapy Programs). Each category of intervention could involve several potential specific activities. For example, for Intervention 3 (DOTS expansion for treatment) activities could include training of doctors, nurses and pharmacists on TB guidelines, monitoring and management of supplies of high quality drugs or translation and printing of training materials for community based DOTS. However, we assumed that these different activities would result in similar impacts in the model, and did not model the impact of these specific activities separately.

\section{Key model parameters affected by intervention}

(Table 1) For each intervention one or more model parameters were assumed to change over time following the intervention. For example for Intervention 2 (DOTS expansion for diagnosis) three different model probabilities were assumed to change (probability of incorrect diagnostic test ordered, diagnostic delay and loss to follow up during diagnostic work up). The interventions, together with corresponding probabilities assumed to change with each intervention, are summarized in Table 1. Many parameters relating to the effect of types of interventions were obtained through a systematic review of published studies of the impact of TB control interventions on TB outcomes and indicators, and were assumed to be the same in all 3 countries. A few pre-intervention parameters varied by country (e.g., frequency of loss to follow up), but most were assumed to be the same in all three countries.

\section{Projected outcomes}

Projected outcomes, over a 20 year time frame, included: primary active cases, secondary active cases generated from primary cases, TB related deaths (during diagnosis or treatment phases), and health system costs (from the perspective of the national health system in the 3 countries).

To better understand the contribution of changing specific model parameters associated with general interventions, projected outcomes were presented separately for each model parameter assumed to be influenced by the intervention. Discounting was not used because a cost effectiveness analysis was not performed, and the primary predicted outcomes were epidemiologic.

\section{Sensitivity analysis}

The individual effect of each key model parameter described in Table 1 was investigated in sensitivity analysis, 
Table 1 Pre and post intervention values for specific model parameters

\begin{tabular}{|c|c|c|c|c|c|}
\hline $\begin{array}{l}\text { Intervention (all public sector } \\
\text { unless otherwise specified) }\end{array}$ & $\begin{array}{l}\text { Model parameters } \\
\text { influenced }\end{array}$ & $\begin{array}{l}\text { Pre-intervention } \\
\text { value }\end{array}$ & $\begin{array}{l}\text { Notes and reference for pre } \\
\text { intervention }\end{array}$ & $\begin{array}{l}\text { Post-intervention } \\
\text { value }\end{array}$ & Notes and Reference for post intervention \\
\hline Community Education & $\begin{array}{l}\text { Patient delay (probability } \\
\text { of seeking care with a } \\
1 \text { year delay) }\end{array}$ & $\begin{array}{l}41 \cdot 79 \text { days }=0 \cdot 11 \\
\text { probability of a } 1 \text { year } \\
\text { delay }\end{array}$ & {$[14-17]$} & $\begin{array}{l}21 \text { days }=0 \cdot 06 \\
\text { probability of a } 1 \\
\text { year delay }\end{array}$ & Assume $50 \%$ reduction in delay days \\
\hline \multirow[t]{3}{*}{ DOTS expansion for diagnosis } & $\begin{array}{l}\text { Incorrect diagnostic test } \\
\text { ordered by heath professional }\end{array}$ & $0 \cdot 603$ & [18] & $0 \cdot 351$ & [19] \\
\hline & $\begin{array}{l}\text { Diagnostic delay (probability } \\
\text { of incurring a } 1 \text { year delay) }\end{array}$ & $\begin{array}{l}29 \cdot 49 \text { days }=0 \cdot 081 \\
\text { probability of a } 1 \text { year } \\
\text { delay }\end{array}$ & {$[14-17]$} & $\begin{array}{l}1 \cdot 83 \text { days }=0 \cdot 005 \\
\text { probability of a } 1 \text { year } \\
\text { delay }\end{array}$ & $\begin{array}{l}\text { Used pre-intervention data and ratio of delay } \\
\text { days "pre" and "post" intervention from [20] } \\
\text { to obtain post-intervention estimate of delay days }\end{array}$ \\
\hline & $\begin{array}{l}\text { Loss to follow up during } \\
\text { diagnostic work-up }\end{array}$ & $0 \cdot 254$ & $\begin{array}{l}\text { [21-24] (Assume that loss to } \\
\text { follow up is the same for } \\
\text { regardless of provider) }\end{array}$ & $0 \cdot 140$ & $\begin{array}{l}\text { Used pre-intervention data and ratio of outcomes } \\
\text { "pre" and "post" intervention from [19] to obtain } \\
\text { post-intervention estimated of loss to follow up }\end{array}$ \\
\hline DOTS Expansion for Treatment & Incorrect treatment & $0 \cdot 791$ & {$[25]$} & $0 \cdot 129$ & $\begin{array}{l}\text { [25] Scenario assumed that incorrect treatment } \\
\text { was given regardless of DST availability }\end{array}$ \\
\hline $\begin{array}{l}\text { Non specific DOTS Expansion } \\
\text { (NTP Strengthening) }\end{array}$ & $\begin{array}{l}\text { Initial access- inaccessible } \\
\text { provider (ie- probability } \\
\text { that patient seeks care with } \\
\text { alternative provider that } \\
\text { is inaccessible to interventions) }\end{array}$ & $0 \cdot 055$ & {$[14,26-31]$} & $0 \cdot 025$ & $\begin{array}{l}\text { Intervention assumed to have same impact as in } \\
\text { private sector }\end{array}$ \\
\hline \multirow[t]{4}{*}{ Private Sector interventions } & $\begin{array}{l}\text { Incorrect diagnostic test } \\
\text { ordered by private provider }\end{array}$ & $0 \cdot 622$ & {$[18]$} & $0 \cdot 362$ & [19] \\
\hline & $\begin{array}{l}\text { Diagnostic delay (private } \\
\text { sector only) }\end{array}$ & $0 \cdot 11$ & [14-17] (\# days pre-intervention) & $0 \cdot 007$ & $\begin{array}{l}\text { Used pre-intervention data and ratio of delay days } \\
\text { "pre" and "post" intervention from [20] to obtain } \\
\text { post-intervention estimate of delay days and then } \\
\text { used ratio of outcomes in public vs private sector } \\
\text { from [14] [27,32,33] to extrapolate estimate for } \\
\text { public system to private system }\end{array}$ \\
\hline & $\begin{array}{l}\text { Loss to follow up during } \\
\text { diagnosis (private sector only) }\end{array}$ & $0 \cdot 254$ & {$[21-24]$} & $0 \cdot 140$ & $\begin{array}{l}\text { Assumed to be same as in public sector (a } 45 \% \\
\text { reduction). Used pre-intervention data and ratio of } \\
\text { outcomes "pre" and "post" intervention from [19] } \\
\text { to obtain post-intervention estimated of drop out }\end{array}$ \\
\hline & $\begin{array}{l}\text { Incorrect treatment by private } \\
\text { provider }\end{array}$ & 0.771 & [34] & $0 \cdot 126$ & $\begin{array}{l}\text { Used pre-intervention data and ratio of outcomes } \\
\text { "pre" and "post" intervention from [25] to obtain } \\
\text { post-intervention estimate of incorrect treatment }\end{array}$ \\
\hline \multirow[t]{3}{*}{ HIV/ ART therapy programmes } & $\begin{array}{l}\text { TB Death rate in HIV/TB } \\
\text { co-infected }\end{array}$ & $0 \cdot 12$ & [35] & $0 \cdot 10$ & $\begin{array}{l}{[35][36,37] \text { (see table } 55 \text { in Supplement appendix }} \\
\text { for more detail) }\end{array}$ \\
\hline & $\begin{array}{l}\text { TB Relapse rate HIV/TB } \\
\text { co-infected }\end{array}$ & $0 \cdot 16$ & {$[36]$} & $0 \cdot 01$ & $\begin{array}{l}{[35][36,37] \text { (see table } 55 \text { in Supplement appendix }} \\
\text { for more detail) }\end{array}$ \\
\hline & $\begin{array}{l}\text { TB Reactivation rate HIV/TB } \\
\text { co-infected }\end{array}$ & $0 \cdot 0340$ & {$[38-40]$} & $0 \cdot 02$ & [41] \\
\hline \multirow[t]{2}{*}{ MDR-TB related interventions } & DST performed & $0 \cdot 2$ & Assumption & $0 \cdot 5$ & Assumption \\
\hline & $\begin{array}{l}\text { MDR- loss to follow up rate } \\
\text { in HIV negative cases }\end{array}$ & $0 \cdot 22$ & {$[36]$} & $0 \cdot 11$ & Assumption- reduce rate to $50 \%$ \\
\hline
\end{tabular}


by considering the impact of an absolute change of $25 \%$ for each parameter. In Indonesia, the sequential impact of implementing several interventions that target the public and private sector together was also considered. In Kazakhstan, the sequential impact of implementing several interventions that first strengthen the general health system, and then improve the diagnosis and treatment of MDR-TB was considered.

\section{Ethics statement}

This study used a hypothetical simulation model based on previously published data, so research ethics committee approval was not required.

\section{Availability of supporting data}

All supporting data used in models are provided in the main text and in accompanying supplementary files.

\section{Results}

Impact of interventions to improve diagnosis and treatment of TB in the public and/or private sectors in a low MDR/low HIV setting. Indonesia case study.

As shown in Table 2, under baseline conditions (no specific intervention) almost two-thirds of active TB cases are predicted to die, and cure rates are very low. This reflects the assumed problems affecting all stages of the patients' trajectory in this baseline scenario, so that very few patients are diagnosed and treated correctly. As a result the number of secondary cases exceeds the reactivated primary cases - implying a net increase in incidence over time under this scenario. The impact of interventions that affect single parameters without changing other parameters, is predicted to be quite modest, as seen in Table 3. Interventions to improve diagnosis in the private and public sectors are predicted to result in the greatest reduction of deaths and secondary cases, while interventions to improve treatment in either sector will result in greatest improvement in cures but with less effect on deaths. Enhancing diagnosis will result in the greatest increase in health system costs, reflecting the costs of putting more people on treatment. Improvements in the diagnosis and treatment of MDR-TB, with greater performance of drug sensitivity testing and reduced default from treatment are predicted to have the least impact. This reflects that in the base case analysis, most patients are not diagnosed with TB at all, thus reducing substantially any possible benefit of improved diagnosis and treatment of MDRTB (which requires that TB is first diagnosed). The sensitivity analysis showing the impact of changing each key parameter by an absolute value of $25 \%$ is shown in Additional file 1: Table S6.

As shown in Figure 1, without any specific interventions, more than $60 \%$ of patients are lost to follow-up when the public or private provider orders an incorrect test, and another $25 \%$ are lost to follow-up prior to being diagnosed correctly. Of those diagnosed correctly, most are then placed on incorrect treatment; as a result less than $10 \%$ start on correct treatment. In Indonesia, where large numbers of TB patients access private providers, improvements only in the public sector will produce some benefits, but the greatest gains will be realized with a combined approach of interventions in both public and private sectors.

When the sequential addition of interventions in the public and private sector was assessed, improved diagnosis in all sectors would substantially reduce deaths and secondary cases, while improved treatment would cause further important reductions in these two outcomes (Table 4). A final reduction to near zero deaths and secondary cases would be achieved by eliminating all patients lost to follow-up prior to the initiation of treatment.

\section{Impact of interventions to improve diagnosis and treatment of TB in a high MDR-TB or high HIV-TB setting. Kazakhstan and Mozambique case studies.}

In Kazakhstan, using the pre-intervention scenario assumptions, a high death rate, low cure rate, and high number of secondary cases are predicted. As with Indonesia, interventions that change individual parameters one at a time will have modest effects (Additional file 1: Table S7). As summarized in Table 5, improved initial diagnosis and improved treatment of DS-TB (with first line drugs) are predicted to have the greatest impact on mortality, the number of secondary cases, and number of cases that are cured. The least impact on these three outcomes would result from isolated improvements in diagnosis of MDR-TB (increasing drug susceptibility testing from $20 \%$ to $50 \%$ of all DR cases), or improving MDR treatment (reducing loss to follow up from $22 \%$ to $11 \%$ ), without any other programmatic changes.

This finding was explored further in sensitivity analysis summarized in Table 6. If the diagnosis and treatment of DS-TB were first improved - with 100\% diagnosis and treatment and eliminating all patients lost to follow-up, but without changes in the MDR-TB program, the number of deaths from TB and secondary cases would fall by almost $70 \%$, while the overall cure rate would increase from $4 \%$ to $75 \%$. If the DR-TB program was also improved - by increasing DST coverage to $100 \%$, and increasing treatment so that $100 \%$ received standard MDR-TB therapy, the overall cure rate would improve from $75 \%$ to $79 \%$. If the MDR-TB regimen included new TB drugs that resulted in cure rates for MDR-TB equivalent to the cure rates now achieved for fully susceptible $\mathrm{TB}$, this would result in an $8 \%$ further reduction in mortality, and an increase in overall cure rate to $84 \%$. 
Table 2 Total projected TB related outcomes per 1,000 general population, in Indonesia over 20 years

\begin{tabular}{|c|c|c|c|c|c|c|c|c|}
\hline \multirow[t]{2}{*}{ Intervention } & \multicolumn{3}{|l|}{ Specific parameter changed $^{1}$} & \multirow{2}{*}{$\begin{array}{l}\text { Primary active } \\
\text { cases arising } \\
\text { in cohort over } \\
20 \text { years }^{3}\end{array}$} & \multicolumn{4}{|c|}{ Total projected outcomes related to the primary cases } \\
\hline & Parameter & Pre-intervention & Post-intervention & & $\begin{array}{l}\text { Death during diagnosis/ } \\
\text { treatment phase }\end{array}$ & $\begin{array}{l}\text { Cure due to } \\
\text { treatment }\end{array}$ & $\begin{array}{l}\text { Secondary cases } \\
\text { generated from } \\
\text { primary cases }\end{array}$ & $\begin{array}{l}\text { Health } \\
\text { system } \\
\text { costs }\end{array}$ \\
\hline Baseline & - & - & - & $19 \cdot 27$ & $12 \cdot 52$ & 0.97 & $28 \cdot 87$ & $\$ 2,641 \cdot 47$ \\
\hline Community Education & Patient delay ${ }^{2}$ & $11 \%$ & $6 \%$ & $19 \cdot 27$ & $12 \cdot 39$ & 0.99 & $28 \cdot 54$ & $\$ 2,696 \cdot 70$ \\
\hline \multirow[t]{3}{*}{$\begin{array}{l}\text { DOTS expansion for } \\
\text { diagnosis }\end{array}$} & $\begin{array}{l}\text { Incorrect Diagnostic } \\
\text { Test (in public sector) }\end{array}$ & $60 \%$ & $35 \%$ & $19 \cdot 27$ & $11 \cdot 90$ & $1 \cdot 24$ & $27 \cdot 38$ & $\$ 3,302 \cdot 55$ \\
\hline & $\begin{array}{l}\text { Diagnostic Delay }{ }^{2} \\
\text { (in public sector) }\end{array}$ & $8 \%$ & $0.5 \%$ & $19 \cdot 27$ & $12 \cdot 48$ & 0.98 & $28 \cdot 71$ & $\$ 2,670 \cdot 63$ \\
\hline & $\begin{array}{l}\text { Loss to follow up during } \\
\text { Diagnosis (in public sector) }\end{array}$ & $25 \%$ & $14 \%$ & $19 \cdot 27$ & $12 \cdot 37$ & $1 \cdot 03$ & $28 \cdot 51$ & $\$ 2,800 \cdot 83$ \\
\hline $\begin{array}{l}\text { DOTS Expansion for } \\
\text { Treatment }\end{array}$ & $\begin{array}{l}\text { Incorrect Treatment (in } \\
\text { public sector) }\end{array}$ & $79 \%$ & $13 \%$ & $19 \cdot 27$ & $12 \cdot 02$ & $2 \cdot 33$ & $27 \cdot 89$ & $\$ 2,646 \cdot 61$ \\
\hline $\begin{array}{l}\text { Non specific DOTS } \\
\text { Expansion (NTP } \\
\text { Strengthening) }\end{array}$ & Access Government Facility & $43 \%$ & $73 \%$ & $19 \cdot 27$ & $12 \cdot 42$ & 0.99 & $28 \cdot 62$ & $\$ 2,764 \cdot 86$ \\
\hline \multirow[t]{4}{*}{$\begin{array}{l}\text { Private Sector } \\
\text { interventions }\end{array}$} & $\begin{array}{l}\text { Incorrect Diagnostic test } \\
\text { (in private sector) }\end{array}$ & $62 \%$ & $36 \%$ & $19 \cdot 27$ & $11 \cdot 75$ & $1 \cdot 33$ & $27 \cdot 04$ & $\$ 3,455 \cdot 53$ \\
\hline & $\begin{array}{l}\text { Diagnostic Delay }{ }^{2} \text { (in private } \\
\text { sector) }\end{array}$ & $11 \%$ & $0 \cdot 7 \%$ & $19 \cdot 27$ & $12 \cdot 46$ & 0.98 & $28 \cdot 63$ & $\$ 2,685 \cdot 49$ \\
\hline & $\begin{array}{l}\text { Loss to follow up during } \\
\text { Diagnosis (in private sector) }\end{array}$ & $25 \%$ & $14 \%$ & $19 \cdot 27$ & $12 \cdot 35$ & $1 \cdot 05$ & $28 \cdot 46$ & $\$ 2,823 \cdot 16$ \\
\hline & $\begin{array}{l}\text { Incorrect Treatment } \\
\text { (in private sector) }\end{array}$ & $77 \%$ & $13 \%$ & $19 \cdot 27$ & $11 \cdot 97$ & $2 \cdot 48$ & $27 \cdot 79$ & $\$ 2,647 \cdot 19$ \\
\hline \multirow{3}{*}{$\begin{array}{l}\text { HIV/ ART therapy } \\
\text { programmes }\end{array}$} & HIV (+) Death & $12 \%$ & $10 \%$ & $19 \cdot 27$ & $12 \cdot 52$ & $0 \cdot 97$ & $28 \cdot 87$ & $\$ 2,641 \cdot 47$ \\
\hline & HIV (+) Relapse & $16 \%$ & $1 \%$ & $19 \cdot 27$ & $12 \cdot 52$ & 0.97 & $28 \cdot 87$ & $\$ 2,641 \cdot 47$ \\
\hline & HIV (+) Reactivation & $3 \cdot 4 \%$ & $2 \%$ & $19 \cdot 26$ & $12 \cdot 52$ & 0.96 & $28 \cdot 86$ & $\$ 2,640 \cdot 66$ \\
\hline \multirow{2}{*}{$\begin{array}{l}\text { MDR-TB related } \\
\text { interventions }\end{array}$} & DST performed & $20 \%$ & $50 \%$ & $19 \cdot 27$ & $12 \cdot 52$ & $0 \cdot 97$ & $28 \cdot 87$ & $\$ 2,693 \cdot 77$ \\
\hline & $\begin{array}{l}\text { Loss to follow up during MDR } \\
\text { Treatment }\end{array}$ & $22 \%$ & $11 \%$ & $19 \cdot 27$ & $12 \cdot 52$ & 0.97 & $28 \cdot 87$ & $\$ 2,642 \cdot 53$ \\
\hline
\end{tabular}

Notes: ${ }^{1}$ See Table 1 for more detail; ${ }^{2}$ Delay $=\%$ with 1 year delay; ${ }^{3}$ Primary cases are those which would arise from reactivation of pre-existing latent TB infection, or progression from newly acquired infection, but do NOT include cases arising from transmission from the primary cases.

(Change in estimate shown represents change relative to baseline for a change in only one parameter and all others remain at pre-intervention values). 
Table 3 Changes in projected TB related outcomes relative to baseline of no intervention, per 1,000 general population, in Indonesia over 20 years

\begin{tabular}{|c|c|c|c|c|c|c|c|c|c|c|c|}
\hline \multirow[t]{3}{*}{ Intervention } & \multicolumn{3}{|l|}{ Specific parameter changed ${ }^{1}$} & \multicolumn{8}{|c|}{ Change in outcomes related to primary active cases and ranking of impact ${ }^{3}$} \\
\hline & \multirow[t]{2}{*}{ Parameter } & \multirow[t]{2}{*}{ Pre-intervention } & \multirow[t]{2}{*}{ Post-intervention } & \multicolumn{2}{|c|}{$\begin{array}{l}\text { Death during diagnosis } \\
\text { and treatment phase }\end{array}$} & \multicolumn{2}{|c|}{ Cure due to treatment } & \multicolumn{2}{|c|}{$\begin{array}{l}\text { Secondary cases generated } \\
\text { from primary cases }\end{array}$} & \multicolumn{2}{|c|}{ Health system costs } \\
\hline & & & & $\begin{array}{l}\text { Change in } \\
\text { outcome }\end{array}$ & $\begin{array}{l}\text { Rank of } \\
\text { impact }\end{array}$ & $\begin{array}{l}\text { Change in } \\
\text { outcome }\end{array}$ & $\begin{array}{l}\text { Rank of } \\
\text { impact }\end{array}$ & $\begin{array}{l}\text { Change in } \\
\text { outcome }\end{array}$ & $\begin{array}{l}\text { Rank of } \\
\text { impact }\end{array}$ & $\begin{array}{l}\text { Change in } \\
\text { outcome }\end{array}$ & $\begin{array}{l}\text { Rank of } \\
\text { impact }\end{array}$ \\
\hline Baseline & - & - & - & $12 \cdot 52$ & - & $0 \cdot 97$ & - & $28 \cdot 87$ & - & $\$ 2,641 \cdot 47$ & - \\
\hline $\begin{array}{l}\text { Community } \\
\text { Education }\end{array}$ & Patient delay ${ }^{2}$ & $11 \%$ & $6 \%$ & $-0 \cdot 14$ & 7 & 0.02 & 7 & $-0 \cdot 33$ & 7 & $55 \cdot 24$ & 10 \\
\hline \multirow[t]{3}{*}{$\begin{array}{l}\text { DOTS expansion } \\
\text { for diagnosis }\end{array}$} & $\begin{array}{l}\text { Incorrect Diagnostic Test } \\
\text { (in public sector) }\end{array}$ & $60 \%$ & $35 \%$ & $-0 \cdot 62$ & 2 & $0 \cdot 27$ & 4 & $-1 \cdot 49$ & 2 & $661 \cdot 09$ & 14 \\
\hline & $\begin{array}{l}\text { Diagnostic Delay }{ }^{2} \text { (in public } \\
\text { sector) }\end{array}$ & $8 \%$ & $0 \cdot 5 \%$ & $-0 \cdot 04$ & 10 & 0.01 & 10 & $-0 \cdot 16$ & 10 & $29 \cdot 16$ & 7 \\
\hline & $\begin{array}{l}\text { Loss to follow up during } \\
\text { Diagnosis (in public sector) }\end{array}$ & $25 \%$ & $14 \%$ & $-0 \cdot 15$ & 6 & $0 \cdot 07$ & 6 & $-0 \cdot 36$ & 6 & $159 \cdot 37$ & 12 \\
\hline $\begin{array}{l}\text { DOTS Expansion } \\
\text { for Treatment }\end{array}$ & $\begin{array}{l}\text { Incorrect Treatment (in public } \\
\text { sector) }\end{array}$ & $79 \%$ & $13 \%$ & $-0 \cdot 50$ & 4 & $1 \cdot 36$ & 2 & $-0 \cdot 98$ & 4 & $5 \cdot 15$ & 5 \\
\hline $\begin{array}{l}\text { Non specific NTP } \\
\text { Strengthening }\end{array}$ & Access Government Facility & $43 \%$ & $73 \%$ & $-0 \cdot 10$ & 8 & $0 \cdot 02$ & 7 & $-0 \cdot 25$ & 8 & $123 \cdot 40$ & 11 \\
\hline \multirow[t]{4}{*}{$\begin{array}{l}\text { Private Sector } \\
\text { interventions }\end{array}$} & $\begin{array}{l}\text { Incorrect Diagnostic test (in } \\
\text { private sector) }\end{array}$ & $62 \%$ & $36 \%$ & $-0 \cdot 77$ & 1 & $0 \cdot 37$ & 3 & $-1 \cdot 84$ & 1 & $814 \cdot 07$ & 15 \\
\hline & $\begin{array}{l}\text { Diagnostic Delay }{ }^{2} \text { (in private } \\
\text { sector) }\end{array}$ & $11 \%$ & $0 \cdot 7 \%$ & $-0 \cdot 07$ & 9 & $0 \cdot 02$ & 7 & $-0 \cdot 24$ & 9 & $44 \cdot 02$ & 8 \\
\hline & $\begin{array}{l}\text { Loss to follow up during } \\
\text { Diagnosis (private sector) }\end{array}$ & $25 \%$ & $14 \%$ & $-0 \cdot 17$ & 5 & $0 \cdot 08$ & 5 & $-0 \cdot 41$ & 5 & $181 \cdot 69$ & 13 \\
\hline & $\begin{array}{l}\text { Incorrect Treatment (in } \\
\text { private sector) }\end{array}$ & $77 \%$ & $13 \%$ & $-0 \cdot 56$ & 3 & $1 \cdot 51$ & 1 & $-1 \cdot 08$ & 3 & $5 \cdot 72$ & 6 \\
\hline \multirow{3}{*}{$\begin{array}{l}\text { HIV/ ART therapy } \\
\text { programmes }\end{array}$} & HIV/TB Death rate & $12 \%$ & $10 \%$ & $0 \cdot 00$ & 11 & $0 \cdot 00$ & 11 & $0 \cdot 00$ & 13 & $0 \cdot 00$ & 2 \\
\hline & HIV/TB Relapse rate & $16 \%$ & $1 \%$ & $0 \cdot 00$ & 11 & $0 \cdot 00$ & 11 & $0 \cdot 00$ & 13 & $0 \cdot 00$ & 2 \\
\hline & HIV/TB Reactivation rate & $3 \cdot 4 \%$ & $2 \%$ & $0 \cdot 00$ & 11 & $0 \cdot 00$ & 11 & $-0 \cdot 01$ & 11 & $-0 \cdot 81$ & 1 \\
\hline \multirow{2}{*}{$\begin{array}{l}\text { MDR-TB related } \\
\text { interventions }\end{array}$} & DST performed & $20 \%$ & $50 \%$ & $0 \cdot 00$ & 11 & $0 \cdot 00$ & 11 & $-0 \cdot 01$ & 11 & $52 \cdot 31$ & 9 \\
\hline & $\begin{array}{l}\text { Loss to follow up during } \\
\text { MDR Treatment }\end{array}$ & $22 \%$ & $11 \%$ & $0 \cdot 00$ & 11 & $0 \cdot 00$ & 11 & $0 \cdot 00$ & 13 & $1 \cdot 07$ & 4 \\
\hline
\end{tabular}

Notes: ${ }^{1}$ See Table 1 for more detail; ${ }^{2}$ Delay $=\%$ with 1 year delay; ${ }^{3}$ Rank of Impact ranks the projected impact of each intervention on each outcome, relative to the baseline of no intervention.

(Change in estimate shown represents change relative to baseline for a change in only one parameter and all others remain at pre-intervention values). 



Figure 1 Probability of intermediate outcomes if interventions are applied in public and or private sectors and achieve improvements in diagnosis and treatment as summarized below, in drug sensitive TB patients, in Indonesia.

When these analyses were repeated using epidemiologic parameters from Mozambique (Tables 7 and 8), without any interventions, the number of deaths are much higher. Increasing ART treatment of HIV coinfected TB patients would result in the greatest reduction in mortality and secondary $\mathrm{TB}$ cases, plus produce net savings to the health system. This is the only intervention that results in a reduction of the number of primary $\mathrm{TB}$ cases, as it actually prevents $\mathrm{TB}$ cases. Interventions that enhance the laboratory network to improve diagnosis would have the next greatest impact.

Table 4 Projected outcomes over 20 years with progressive addition of interventions that improve the public and private sectors for TB care in Indonesia (per 1000 persons from general population)

\begin{tabular}{|c|c|c|c|c|c|c|}
\hline \multirow[t]{2}{*}{ Scenario } & \multirow{2}{*}{$\begin{array}{l}\text { Primary active cases } \\
\text { arising in cohort } \\
\text { over } 20 \text { years }^{1}\end{array}$} & \multicolumn{5}{|c|}{ Total projected outcomes related to the primary active cases } \\
\hline & & $\begin{array}{l}\text { Death during } \\
\text { diagnosis phase }\end{array}$ & $\begin{array}{l}\text { Death during } \\
\text { treatment phase }\end{array}$ & $\begin{array}{l}\text { Cure due to } \\
\text { treatment }\end{array}$ & $\begin{array}{l}\text { Secondary cases } \\
\text { generated from } \\
\text { primary cases }\end{array}$ & $\begin{array}{l}\text { Health system } \\
\text { costs }\end{array}$ \\
\hline Baseline & $19 \cdot 27$ & $11 \cdot 01$ & $1 \cdot 51$ & 0.97 & $28 \cdot 87$ & $\$ 2,641 \cdot 47$ \\
\hline $\begin{array}{l}\text { Eliminate patient delay } \\
\text { in seeking care }\end{array}$ & $19 \cdot 27$ & $10 \cdot 67$ & $1 \cdot 57$ & $1 \cdot 01$ & $28 \cdot 21$ & $\$ 2,751 \cdot 94$ \\
\hline $\begin{array}{l}\text { Above \& Eliminate } \\
\text { informal sector for } \\
\text { TB diagnosis }\end{array}$ & $19 \cdot 27$ & $10 \cdot 45$ & $1 \cdot 67$ & $1 \cdot 06$ & $27 \cdot 88$ & $\$ 2,916 \cdot 34$ \\
\hline $\begin{array}{l}\text { Above \& Increase } \\
\text { correct diagnostic } \\
\text { test to } 100 \%\end{array}$ & $19 \cdot 27$ & $4 \cdot 11$ & $4 \cdot 31$ & $2 \cdot 75$ & $18 \cdot 64$ & $\$ 6,809 \cdot 05$ \\
\hline $\begin{array}{l}\text { Above \& Eliminate } \\
\text { health system } \\
\text { diagnostic delay }\end{array}$ & $19 \cdot 27$ & $3 \cdot 67$ & $4 \cdot 44$ & $2 \cdot 84$ & $17 \cdot 40$ & $\$ 7,013 \cdot 83$ \\
\hline $\begin{array}{l}\text { Above \& Increase } \\
\text { correct treatment } \\
\text { to } 100 \%\end{array}$ & $19 \cdot 27$ & $3 \cdot 67$ & 0.72 & $12 \cdot 95$ & $9 \cdot 59$ & $\$ 7,052 \cdot 06$ \\
\hline $\begin{array}{l}\text { Above \& Eliminate } \\
\text { loss to follow up } \\
\text { prior to starting } \\
\text { treatment }\end{array}$ & $19 \cdot 27$ & 0 & 0.96 & $17 \cdot 35$ & $1 \cdot 39$ & $\$ 9,295 \cdot 09$ \\
\hline
\end{tabular}

'Primary cases are those which would arise from reactivation of pre-existing latent TB infection, or progression from newly acquired infection, but do NOT include cases arising from transmission from the primary cases. 
Table 5 Changes in projected TB related outcomes relative to baseline of no intervention per 1,000 general population, in Kazakhstan over 20 years

\begin{tabular}{|c|c|c|c|c|c|c|c|c|c|c|c|}
\hline \multirow[t]{3}{*}{$\begin{array}{l}\text { General } \\
\text { intervention }\end{array}$} & \multicolumn{3}{|l|}{ Specific parameter changed ${ }^{1}$} & \multicolumn{8}{|c|}{$\begin{array}{l}\text { Projected changes in outcomes related to the primary active cases and Ranking of } \\
\text { impact }^{3}\end{array}$} \\
\hline & \multirow[t]{2}{*}{ Parameter } & \multirow[t]{2}{*}{ Pre-intervention } & \multirow[t]{2}{*}{ Post-intervention } & \multicolumn{2}{|c|}{$\begin{array}{l}\text { Death during diagnosis } \\
\text { and treatment phase }\end{array}$} & \multicolumn{2}{|l|}{$\begin{array}{l}\text { Cure due to } \\
\text { treatment }\end{array}$} & \multicolumn{2}{|c|}{$\begin{array}{l}\text { Secondary cases } \\
\text { generated from } \\
\text { primary cases }\end{array}$} & \multicolumn{2}{|c|}{$\begin{array}{l}\text { Health system } \\
\text { costs }\end{array}$} \\
\hline & & & & $\begin{array}{l}\text { Change in } \\
\text { outcome }\end{array}$ & $\begin{array}{l}\text { Rank of } \\
\text { impact }\end{array}$ & $\begin{array}{l}\text { Change in } \\
\text { outcome }\end{array}$ & $\begin{array}{l}\text { Rank of } \\
\text { impact }\end{array}$ & $\begin{array}{l}\text { Change in } \\
\text { outcome }\end{array}$ & $\begin{array}{l}\text { Rank of } \\
\text { impact }\end{array}$ & $\begin{array}{l}\text { Change in } \\
\text { outcome }\end{array}$ & $\begin{array}{l}\text { Rank of } \\
\text { impact }\end{array}$ \\
\hline Baseline outcomes & - & - & - & $10 \cdot 05$ & & 0.62 & & $22 \cdot 99$ & & $\$ 5,238 \cdot 87$ & \\
\hline $\begin{array}{l}\text { Community } \\
\text { Education }\end{array}$ & Patient delay ${ }^{2}$ & $11 \%$ & $6 \%$ & $-0 \cdot 14$ & 3 & $0 \cdot 01$ & 5 & $-0 \cdot 26$ & 5 & $111 \cdot 34$ & 3 \\
\hline \multirow{3}{*}{$\begin{array}{l}\text { DOTS expansion for } \\
\text { diagnosis }\end{array}$} & Incorrect Diagnostic Test & $60 \%$ & $35 \%$ & $-1 \cdot 88$ & 1 & $0 \cdot 40$ & 2 & $-2 \cdot 47$ & 1 & $2947 \cdot 81$ & 9 \\
\hline & Diagnostic Delay ${ }^{2}$ & $8 \%$ & $0 \cdot 5 \%$ & $-0 \cdot 11$ & 4 & 0.02 & 4 & $-0 \cdot 27$ & 4 & $132 \cdot 69$ & 4 \\
\hline & Loss to follow up during Diagnosis & $25 \%$ & $14 \%$ & $-0 \cdot 45$ & 2 & $0 \cdot 10$ & 3 & $-0 \cdot 60$ & 3 & $710 \cdot 63$ & 8 \\
\hline $\begin{array}{l}\text { DOTS Expansion for } \\
\text { Treatment }\end{array}$ & Incorrect Treatment & $79 \%$ & $13 \%$ & 0.00 & 6 & $1 \cdot 98$ & 1 & $-1 \cdot 54$ & 2 & $363 \cdot 20$ & 7 \\
\hline $\begin{array}{l}\text { Non specific DOTS } \\
\text { Expansion (NTP } \\
\text { Strengthening) }\end{array}$ & Access Government Facility & $94 \cdot 5 \%$ & $97 \cdot 5 \%$ & $-0 \cdot 09$ & 5 & 0.02 & 4 & $-0 \cdot 12$ & 6 & $164 \cdot 65$ & 5 \\
\hline \multirow{3}{*}{$\begin{array}{l}\text { HIV/ ART therapy } \\
\text { programmes }\end{array}$} & HIV/TB Death rate & $12 \%$ & $10 \%$ & $0 \cdot 00$ & 6 & 0.00 & 6 & $0 \cdot 00$ & 8 & $0 \cdot 00$ & 2 \\
\hline & HIV/TB Relapse rate & $16 \%$ & $1 \%$ & $0 \cdot 00$ & 6 & $0 \cdot 00$ & 6 & $0 \cdot 00$ & 8 & 0.00 & 2 \\
\hline & HIV/TB Reactivation rate & $3 \cdot 4 \%$ & $2 \%$ & $0 \cdot 00$ & 7 & 0.01 & 5 & $0 \cdot 05$ & 9 & $-142 \cdot 43$ & 1 \\
\hline \multirow{2}{*}{$\begin{array}{l}\text { MDR-TB related } \\
\text { interventions }\end{array}$} & DST performed & $20 \%$ & $50 \%$ & 0.00 & 6 & 0.02 & 4 & $-0 \cdot 03$ & 7 & $232 \cdot 19$ & 6 \\
\hline & $\begin{array}{l}\text { Loss to follow up during MDR } \\
\text { Treatment }\end{array}$ & $22 \%$ & $11 \%$ & $0 \cdot 00$ & 6 & $0 \cdot 00$ & 6 & $0 \cdot 00$ & 8 & $10 \cdot 11$ & 3 \\
\hline
\end{tabular}

Notes: ${ }^{1}$ See Table 1 for more detail; ${ }^{2}$ Delay $=\%$ with 1 year delay; ${ }^{3}$ Rank of Impact ranks the projected impact of each intervention on each outcome, relative to the baseline of no intervention.

(Change in estimate shown represents change relative to baseline for a change in only one parameter and all others remain at pre-intervention values). 
Table 6 Projected outcomes over 20 years with progressive addition of interventions that improve general TB services plus MDR diagnosis and treatment in Kazakhstan (per 1000 persons from general population)

\begin{tabular}{|c|c|c|c|c|c|c|}
\hline \multirow{2}{*}{$\begin{array}{l}\text { Category of } \\
\text { intervention }\end{array}$} & \multirow[t]{2}{*}{ Scenario } & \multirow{2}{*}{$\begin{array}{l}\text { Primary active } \\
\text { cases arising in } \\
\text { cohort over } \\
20 \text { years }^{1}\end{array}$} & \multicolumn{4}{|c|}{ Total projected outcomes related to the primary active cases } \\
\hline & & & $\begin{array}{l}\text { Death during } \\
\text { diagnosis and } \\
\text { treatment phase }\end{array}$ & $\begin{array}{l}\text { Cure due } \\
\text { to treatment }\end{array}$ & $\begin{array}{l}\text { Secondary cases } \\
\text { generated from } \\
\text { primary cases }\end{array}$ & $\begin{array}{l}\text { Health system } \\
\text { costs }\end{array}$ \\
\hline & Baseline & $15 \cdot 28$ & $10 \cdot 05$ & $0 \cdot 62$ & $22 \cdot 99$ & $\$ 5,238 \cdot 87$ \\
\hline \multirow[t]{3}{*}{$\begin{array}{l}\text { General Health } \\
\text { System Interventions }\end{array}$} & $\begin{array}{l}\text { Improved diagnosis to detect } \\
100 \% \text { of TB cases in public } \\
\text { sector (DS and MDR) }\end{array}$ & $15 \cdot 28$ & $7 \cdot 67$ & $1 \cdot 57$ & $17 \cdot 07$ & $\$ 12,292 \cdot 55$ \\
\hline & $\begin{array}{l}\text { Above \& improved treatment } \\
\text { to achieve } 100 \% \text { cure for DS } \\
\text { in public sector }\end{array}$ & $15 \cdot 28$ & $4 \cdot 96$ & $8 \cdot 60$ & $12 \cdot 22$ & $\$ 12,354 \cdot 14$ \\
\hline & $\begin{array}{l}\text { Above \& reduced loss to follow } \\
\text { up in public sector }\end{array}$ & $15 \cdot 28$ & $2 \cdot 70$ & $11 \cdot 53$ & $7 \cdot 23$ & $\$ 16,351 \cdot 62$ \\
\hline \multirow[t]{3}{*}{$\begin{array}{l}\text { MDR-TB related } \\
\text { interventions }\end{array}$} & $\begin{array}{l}\text { Above \& Improve DST coverage } \\
\text { to } 100 \%\end{array}$ & $15 \cdot 28$ & $2 \cdot 59$ & $11 \cdot 72$ & $6 \cdot 96$ & $\$ 18,441 \cdot 46$ \\
\hline & $\begin{array}{l}\text { Above \& Improved treatment } \\
\text { coverage so that all MDR cases } \\
\text { diagnosed get standard MDR } \\
\text { therapy }\end{array}$ & $15 \cdot 28$ & $2 \cdot 07$ & $12 \cdot 61$ & $5 \cdot 66$ & $\$ 27,327 \cdot 96$ \\
\hline & $\begin{array}{l}\text { Above \& New MDR drugs so } \\
\text { treatment outcomes are as } \\
\text { good as drug sensitive TB cases }\end{array}$ & $15 \cdot 28$ & $1 \cdot 85$ & $13 \cdot 11$ & $5 \cdot 41$ & $\$ 28,513 \cdot 34$ \\
\hline
\end{tabular}

${ }^{1}$ Primary cases are those which would arise from reactivation of pre-existing latent TB infection, or progression from newly acquired infection, but do NOT include cases arising from transmission from the primary cases.

\section{Discussion}

In our study, the greatest gains in reducing $\mathrm{TB}$ deaths and secondary cases are expected to come from interventions that reduce the reactivation rate to disease (ie. ART for HIV co-infected patients), or affect all patients with TB disease early in their trajectory, by improving their diagnosis. Further gains are made if treatment is also improved. In settings with a prominent private sector such as Indonesia, these achievements will be even greater if interventions are directed to both the public and private sectors. Even in settings with high levels of MDR-TB, we predict that interventions that improve diagnosis of all TB patients plus treat DS-TB cases correctly will have greater overall impact. The finding that the foundation for successful scale up of interventions is the strengthening of initial diagnosis and appropriate timely treatment of persons with TB supports current WHO recommendations for health system strengthening, TB prevention, diagnosis and treatment programs [42].

In the base case scenario, TB related mortality rates are projected to be very high in all settings, reflecting very low overall rates of successful diagnosis and treatment. In the model, TB cases that are undiagnosed die at rates consistent with those reported for smear positive cases in the pre-antibiotic era (approximately 33\% per year [43]). In recent national prevalence surveys the number of TB cases that are undiagnosed has been found to be remarkably high. For example, in Nigeria, the case detection rate is now estimated to be only $16 \%$, and TB mortality was found to be $400 \%$ higher than previously estimated rates [3]. Indonesia has also recently completed a prevalence survey but results are not yet published. In the 2014 Global TB report however, WHO suggests that results will lead to revisions of previously published global TB estimates [3].

The interventions included in this analysis are those most commonly introduced for TB prevention, diagnosis and treatment in LMIC as part of Stop TB Global plans, and were restricted to those for which there is published evidence of their potential impact. Several interventions were initially considered but ultimately excluded for the following reasons: 1) There was insufficient published data regarding their effect, 2) They had an overarching effect that influenced multiple elements within the conceptual framework so a precise effect within the model could not be assumed, or 3) published pre-intervention estimates were already excellent. The independent effects of each intervention can be very difficult to assess in field studies because in most countries multiple interventions have been applied simultaneously. Other modeling studies have considered the relative impact of different interventions [44-46], but not the impact of multiple interventions, nor multiple sectors. In this 
Table 7 Total projected TB related outcomes per 1,000 population, in Mozambique over 20 years

\begin{tabular}{|c|c|c|c|c|c|c|c|c|}
\hline \multirow[t]{2}{*}{ Interventions } & \multicolumn{3}{|l|}{ Specific parameter change $^{1}$} & \multirow{2}{*}{$\begin{array}{l}\text { Primary active cases } \\
\text { arising in cohort over } \\
20 \text { years }^{3}\end{array}$} & \multicolumn{4}{|c|}{ Total projected outcomes related to the primary cases } \\
\hline & Parameter & Pre & Post & & $\begin{array}{l}\text { Death during diagnosis and } \\
\text { treatment phase }\end{array}$ & $\begin{array}{l}\text { Cure due to } \\
\text { treatment }\end{array}$ & $\begin{array}{l}\text { Secondary cases } \\
\text { generated from } \\
\text { primary cases }\end{array}$ & $\begin{array}{l}\text { Health system } \\
\text { cost }\end{array}$ \\
\hline Baseline & - & - & - & 69.82 & 47.34 & 2.40 & 106.05 & $\$ 2,818.01$ \\
\hline Community Education & Patient delay ${ }^{2}$ & $11 \%$ & $6 \%$ & 69.82 & 45.97 & 2.51 & 104.24 & $\$ 2,955.56$ \\
\hline \multirow[t]{3}{*}{ DOTS expansion for diagnosis } & Incorrect Diagnostic Test & $60 \%$ & $35 \%$ & 69.82 & 39.57 & 3.92 & 94.82 & $\$ 4,075.36$ \\
\hline & Diagnostic Delay $^{2}$ & $8 \%$ & $0.5 \%$ & 69.82 & 46.29 & 2.54 & 104.44 & $\$ 2,942.14$ \\
\hline & $\begin{array}{l}\text { Loss to follow up during } \\
\text { diagnosis }\end{array}$ & $25 \%$ & $14 \%$ & 69.82 & 45.47 & 2.76 & 103.35 & $\$ 3,121.12$ \\
\hline DOTS Expansion for Treatment & Incorrect Treatment & $79 \%$ & $13 \%$ & 69.82 & 47.34 & 10.00 & 99.21 & $\$ 2,920.66$ \\
\hline $\begin{array}{l}\text { Non specific DOTS Expansion } \\
\text { (NTP Strengthening) }\end{array}$ & Access Government Facility & $94.5 \%$ & $97.5 \%$ & 69.82 & 46.96 & 2.47 & 105.50 & $\$ 2,906.57$ \\
\hline \multirow[t]{3}{*}{ HIV/ ART therapy programmes } & HIV/TB Death rate & $12 \%$ & $10 \%$ & 69.82 & 47.34 & 2.45 & 106.05 & $\$ 2,818.01$ \\
\hline & HIV/TB Relapse rate & $16 \%$ & $1 \%$ & 69.82 & 47.34 & 2.70 & 105.93 & $\$ 2,818.01$ \\
\hline & HIV/TB Reactivation rate & $3.4 \%$ & $2 \%$ & 57.11 & 39.55 & 2.01 & 86.58 & $\$ 2,326.66$ \\
\hline \multirow[t]{2}{*}{ MDR-TB related interventions } & DST performed & $20 \%$ & $50 \%$ & 69.82 & 47.34 & 2.41 & 106.02 & $\$ 2,986.38$ \\
\hline & $\begin{array}{l}\text { Loss to follow up during } \\
\text { MDR Treatment }\end{array}$ & $22 \%$ & $11 \%$ & 69.82 & 47.34 & 2.40 & 106.05 & $\$ 2,819.07$ \\
\hline
\end{tabular}

Notes: ${ }^{1}$ See Table 1 for more detail; ${ }^{2}$ Delay $=\%$ with 1 year delay; ${ }^{3}$ Primary cases are those which would arise from reactivation of pre-existing latent TB infection, or progression from newly acquired infection, but do

NOT include cases arising from transmission from the primary cases.

(Change in estimate shown represents change relative to baseline for a change in only one parameter and all others remain at pre-intervention values). 
Table 8 Changes in projected TB related outcomes per 1,000 population, in Mozambique over 20 years

\begin{tabular}{|c|c|c|c|c|c|c|c|}
\hline \multirow[t]{2}{*}{ General intervention } & \multicolumn{3}{|c|}{ Specific parameter changed $^{1}$} & \multicolumn{4}{|c|}{ Projected changes in outcomes related to the primary active cases } \\
\hline & Parameter & Pre & Post & $\begin{array}{l}\text { Death during diagnosis } \\
\text { and treatment phase }\end{array}$ & $\begin{array}{l}\text { Cure due to } \\
\text { treatment }\end{array}$ & $\begin{array}{l}\text { Secondary cases } \\
\text { generated from } \\
\text { primary cases }\end{array}$ & $\begin{array}{l}\text { Health system } \\
\text { costs }\end{array}$ \\
\hline Baseline outcomes & - & - & - & 47.34 & 2.40 & 106.05 & $\$ 2,818.01$ \\
\hline Community Education & Patient delay ${ }^{2}$ & $11 \%$ & $6 \%$ & -1.37 & 0.11 & -1.82 & 137.55 \\
\hline \multirow[t]{3}{*}{$\begin{array}{l}\text { DOTS expansion for } \\
\text { diagnosis }\end{array}$} & $\begin{array}{l}\text { Incorrect Diagnostic } \\
\text { Test }\end{array}$ & $60 \%$ & $35 \%$ & -7.77 & 1.52 & -11.23 & 1257.35 \\
\hline & Diagnostic Delay ${ }^{2}$ & $8 \%$ & $0.5 \%$ & -1.05 & 0.14 & -1.61 & 124.13 \\
\hline & $\begin{array}{l}\text { Drop out during } \\
\text { Diagnosis }\end{array}$ & $25 \%$ & $14 \%$ & -1.87 & 0.37 & -2.71 & 303.11 \\
\hline $\begin{array}{l}\text { DOTS Expansion for } \\
\text { Treatment }\end{array}$ & Incorrect Treatment & $79 \%$ & $13 \%$ & 0.00 & 7.61 & -6.84 & 102.65 \\
\hline $\begin{array}{l}\text { Non specific DOTS } \\
\text { Expansion (NTP } \\
\text { Strengthening) }\end{array}$ & $\begin{array}{l}\text { Access Government } \\
\text { Facility }\end{array}$ & $94.5 \%$ & $97.5 \%$ & -0.38 & 0.08 & -0.56 & 88.57 \\
\hline \multirow{3}{*}{$\begin{array}{l}\text { HIV/ ART therapy } \\
\text { programmes }\end{array}$} & HIV/TB Death rate & $12 \%$ & $10 \%$ & 0.00 & 0.05 & 0.00 & 0.00 \\
\hline & HIV/TB Relapse rate & $16 \%$ & $1 \%$ & 0.00 & 0.30 & -0.12 & 0.00 \\
\hline & $\begin{array}{l}\text { HIV/TB Reactivation } \\
\text { rate }\end{array}$ & $3.4 \%$ & $2 \%$ & -7.79 & -0.39 & -19.47 & -491.35 \\
\hline \multirow{2}{*}{$\begin{array}{l}\text { MDR-TB related } \\
\text { interventions }\end{array}$} & DST performed & $20 \%$ & $50 \%$ & 0.00 & 0.02 & -0.03 & 168.37 \\
\hline & $\begin{array}{l}\text { Loss to follow up } \\
\text { during MDR } \\
\text { Treatment }\end{array}$ & $22 \%$ & $11 \%$ & 0.00 & 0.00 & 0.00 & 1.06 \\
\hline
\end{tabular}

Notes: ${ }^{1}$ See Table 1 for more detail; ${ }^{2}$ Delay $=\%$ with 1 year delay.

(Change in estimate shown represents change relative to baseline for a change in only one parameter and all others remain at pre-intervention values).

study we compared the relative impact of interventions separately, in combination, and across multiple sectors which is more realistic. In addition, our study included health system costs which were not considered in detail in other studies which modeled epidemiologic outcomes [44-46].

Nevertheless this study has several limitations. First, although the number of secondary cases that originate from active cases were predicted in our model, these cases do not influence the annual risk of infection in subsequent years. Thus the population level impact of interventions was not directly evaluated and our findings are likely conservative. This limitation has implications particularly for DR-TB interventions, because preventing transmission (through prompt diagnosis and effective treatment) is an important goal. In all 3 countries modeled, interventions directed at improved diagnosis or treatment of MDR-TB were projected to have less impact than interventions to prevent primary cases, or to enhance early diagnosis of all TB cases. This is because patients with MDR-TB must first be diagnosed with TB, in order to have DST performed. Hence performing DST on a small fraction of all cases (when all the remaining cases have not been diagnosed at all) will inevitably have less impact than if diagnosis of all cases is improved first, since MDR-TB cases can only be diagnosed with DST. We also found that improving treatment of DS-TB cases would have more impact than improving treatment of MDR-TB, even when we assumed very high cure rates - similar to recently reported cure rates with new shorter MDR regimens [47]. This reflects the fact that even in a high MDR prevalence setting the majority of cases $(>70 \%)$ are DSTB. This is also combined with the fact that DS-TB regimens have a greater treatment success rate (averaging $>90 \%$ [48]) than do MDR-TB regimens (averaging $55-60 \%[36])$. As detection of DS-TB continues to improve, the impact of MDR-TB interventions will also have the potential to improve.

Second, the magnitude of the effect sizes for some of the interventions were large. Studies that documented the effect of interventions were identified through an extensive review of the literature, but some of these improvements were reported from single studies, some of which involved small study populations, or had short periods of follow-up. It is unclear if these improvements could be obtained or sustained when applied on a national scale. Finally, we could not perform a comprehensive cost effectiveness study, because the costs associated with interventions were not available from the studies that reported outcomes resulting from these interventions. This emphasizes the need for systematic collection and 
reporting of cost data in future studies of similar interventions.

In the post 2015 era there has been a call to accelerate progress by building on national and global efforts that have already had an impact on TB indicators $[42,49]$. Our sensitivity analysis on TB mortality (Table 4) considered in detail the substantial effort that will be required to meet the WHO goal of zero TB deaths. Scale up and strengthening of interventions like those included in our analysis should help to accelerate progress toward these ambitious goals, however the rate at which gains can be made will depend on the both the ongoing political and financial commitment to combat TB at both a global and national level.

\section{Conclusion}

In all settings, the greatest benefit will come from interventions that reduce reactivation to disease, or those that increase early diagnosis and improve treatment for DS-TB as well as DR-TB. Once this has been achieved more specific interventions, such as those targeting HIV, drug resistance or the private sector can be integrated to increase impact. The findings of this study may provide useful information to guide selection of TB interventions in different settings, particularly as programs begin to scale-up interventions in the private sector and financial schemes are developed and improved to address universal health coverage.

\section{Additional file}

Additional file 1: Figure S1. Framework for the natural history of TB disease, and opportunities for intervention. Figure S2. Summary of optimal patient trajectory and sub-optimal alternatives where interventions may be applied. Supplement Table S1. Epidemiology, Pathogenesis and Natural History parameters. Supplement Methods Table S2. Pre-Intervention (Baseline) Diagnostic and Treatment Related Parameters. Supplement Methods Table S3. Pre-Intervention Treatment outcomes with and without Drug Susceptibility Testing (DST). Supplement Methods Table S4. Summary of TB related Health System costs (All Costs in 2010 US dollars). Supplement Methods Table S5. Impact of Antiretroviral Therapy (ART) on TB TREATMENT OUTCOMES for TB/HIV positive patients, with and without Drug sensitivity testing (DST). Supplement Results Table S6. Sensitivity Analysis- Indonesia, Absolute change of $25 \%$ for key variables by intervention. Each variable run at assumed value of 25\% and then at 50\% (all other variables as per baseline scenario). Supplement Results Table S7. Total Projected TB related outcomes per 1,000 population, in Kazakhstan over 20 years.

\section{Abbreviations}

USAID: United States Agency for International Development; TB: Tuberculosis; LMIC: Low and Middle Income Countries; HIV: Human Immuno-deficiency Virus; AIDS: Acquired Immuno Deficiency Syndrome; MDR-TB: Multi-Drug Resistant Tuberculosis; WHO: World Health Organization; GDF: Global Drug Facility; NTP: National Tuberculosis Program; MDG: Millennium Development Goals; MDR-TB: Multi Drug Resistant Tuberculosis; DS-TB: Drug Sensitive Tuberculosis; DST: Drug Sensitivity Testing; ART: Anti-Retroviral Therapy; DOTS: Directly Observed Therapy Short-course.

\section{Competing interests}

The authors declare that they have no competing interests.

\section{Authors' contributions}

AP and CV conceived the study idea. OO, AP, CV and DM contributed to the study design. $\mathrm{OO}$ and DM conducted the literature review and data analysis. OO, AP, CV and DM contributed to data interpretation. OO, AP, CV and DM contributed to writing the manuscript and approved the final version of the paper.

\section{Acknowledgments}

This study was funded by the United States Agency for International Development. We have not entered into an agreement with the funder that has limited our ability to complete the research as planned. We have had full control of all primary data.

\section{Disclaimer}

This manuscript was made possible by the generous support of the American people through the United States Agency for International Development (USAID). The findings and conclusions in this paper are those of the authors and do not necessarily represent the official position of USAID.

\section{Author details}

${ }^{1}$ McGill University and the McGill International TB Centre, Montreal, Canada. ${ }^{2}$ Montreal Chest Institute, 3650 St. Urbain St, Montréal H2X 2P4, PQ, Canada.

${ }^{3}$ United States Agency for International Development, Washington, DC, USA.

Received: 15 September 2014 Accepted: 27 January 2015

Published online: 13 February 2015

\section{References}

1. Stop TB Partnership, [http://stoptb.org/global/plan/], Access Date January 142015

2. Global Drug Facility, [http://www.stoptb.org/gdf/drugsupply/pc2.asp? CLevel=2\&CParent=4], Access Date January 142015

3. World Health Organization. Global Tuberculosis Report 2014. Geneva: World Health Organization; 2014.

4. Floyd K, Fitzpatrick C, Pantoja A, Raviglione M. Domestic and donor financing for tuberculosis care and control in low-income and middle-income countries: an analysis of trends, 2002-11, and requirements to meet 2015 targets. The Lancet Global Health. 2013;1(2):e105-15.

5. World Health Organization and UNICEF. Countdown to 2015: building a future for women and children. Washington DC: UNICEF; 2012.

6. WHO End TB Strategy [http://www.who.int/tb/post2015_strategy/en/], Access Date January 142015

7. World Health Organization. Anti-tuberculosis drug resistance in the world: the WHO/IUATLD Global Project on Anti-Tuberculosis Drug Resistance Surveillance. Fourth global report. Geneva, Switzerland: WHO; 2008.

8. World Health Organization. Global Tuberculosis Report 2012. Geneva: World Health Organization; 2012.

9. World Health Organization: HIV Global Database. [apps.who.int/gho/data/], Access Date January 142015

10. Law S, Benedetti A, Oxlade O, Schwartzman K, Menzies D. Comparing costeffectiveness of standardised tuberculosis treatments given varying drug resistance. Eur Respir J. 2014:43(2):566-81.

11. Jacquet V, Morose W, Schwartzman K, Oxlade O, Barr G, Grimard F, et al. Impact of DOTS expansion on tuberculosis related outcomes and costs in Haiti. BMC Public Health. 2006;6(1):209.

12. The World Bank, [www.worldbank.org], Access Date January 142015

13. World Health Organization: WHO CHOICE Costing tool. [http://www.who. int/choice/cost-effectiveness/inputs/en/]. Access Date January 142015

14. World Health Organization. Diagnostic and Treatment Delay in Tuberculosis. An In-Depth Analysis of the Health-Seeking Behaviour of Patients and Health System response in seven Countries of the Eastern Mediterranean Region. Geneva, Switzerland: World Health Organization; 2006.

15. Storla DG, Yimer S, Bjune GA. A systematic review of delay in the diagnosis and treatment of tuberculosis. BMC Public Health. 2008;8(1):15.

16. Sreeramareddy CT, Panduru KV, Menten J, Van den Ende J. Time delays in diagnosis of pulmonary tuberculosis: a systematic review of literature. BMC Infect Dis. 2009:9(1):91.

17. Steffen R, Menzies D, Oxlade O, Pinto M, de Castro AZ, Monteiro P, et al. Patients' costs and cost-effectiveness of tuberculosis treatment in DOTS and non-DOTS facilities in Rio de Janeiro Brazil. PLoS One. 2010;5(11):e14014. 
18. Vandan N, Ali M, Prasad R, Kuroiwa C. Assessment of doctors' knowledge regarding tuberculosis management in Lucknow, India: A public-private sector comparison. Public Health. 2009;123(7):484-9.

19. Davis J, Katamba A, Vasquez J, Crawford E, Sserwanga A, Kakeeto S, et al. Evaluating tuberculosis case detection via real-time monitoring of tuberculosis diagnostic services. Am J Respir Crit Care Med. 2011:184(3):362-7.

20. Boehme C, Nicol M, Nabeta P, Michael J, Gotuzzo E. Feasibility and impact of decentralised use of Xpert MTB/RIF for the diagnosis of tuberculosis and multi-drug resistance-results from a multi-center implementation study. Lancet. 2011;377(9776):1495-505.

21. Long Q, Li Y, Wang Y, Yue Y, Tang C, Tang S, et al. Barriers to accessing TB diagnosis for rural-to-urban migrants with chronic cough in Chongqing, China: a mixed methods study. BMC Health Serv Res. 2008;8(1):202.

22. Krishnan A, Kapoor S. Involvement of private practitioners in tuberculosis control in Ballabgarh, Northern India. Int J Tuberc Lung Dis. 2006;10(3):264-9.

23. Khan MS, Khan S, Godfrey Faussett P. Default during TB diagnosis: quantifying the problem. Trop Med Int Health. 2009;14(12):1437-41.

24. Dembele S, Ouédraogo H, Combary A, Sondo B, Macq J, Dujardin B. Are patients who present spontaneously with PTB symptoms to the health services in Burkina Faso well managed? Int J Tuberc Lung Dis. 2006;10(4):436-40.

25. Tuberculosis Control Assistance Program, Indonesia. USAID. In: collaboration with the Ministry of Health. Jakarta, Indonesia: Indonesia National TB Control Program; 2006

26. USAID and TBCAREII. Results of desktop review: Reducing delays in TB diagnosis: Develop methods to evaluate the frequency and causes of delays. Washington DC: USAID; 2011.

27. Selvam JM, Wares F, Perumal M, Gopi P, Sudha G, Chandrasekaran V, et al. Health-seeking behaviour of new smear-positive TB patients under a DOTS programme in Tamil Nadu, India, 2003. Int J Tuberc Lung Dis. 2007;11(2):161-7.

28. Satyanarayana S, Nair SA, Chadha SS, Shivashankar R, Sharma G, Yadav S, et al. From where are tuberculosis patients accessing treatment in India? Results from a cross-sectional community based survey of 30 districts. PLoS One. 2011;6(9):e24160.

29. Yamasaki-Nakagawa M, Ozasa K, Yamada N, Osuga K, Shimouchi A, Ishikawa N, et al. Gender difference in delays to diagnosis and health care seeking behaviour in a rural area of Nepal. Int J Tuberc Lung Dis. 2001;5(1):24-31.

30. Lienhardt C, Rowley J, Manneh K, Lahai G, Needham D, Milligan P, et al. Factors affecting time delay to treatment in a tuberculosis control programme in a sub-Saharan African country: the experience of The Gambia. Int J Tuberc Lung Dis. 2001:5(3):233-9.

31. Mahendradhata $Y$, Syahrizal BM, Utarini A. Delayed treatment of tuberculosis patients in rural areas of Yogyakarta province Indonesia. BMC Public Health. 2008;8(1):393.

32. Rojpibulstit M, Kanjanakiritamrong J, Chongsuvivatwong V. Patient and health system delays in the diagnosis of tuberculosis in Southern Thailand after health care reform. Int J Tuberc Lung Dis. 2006;10(4):422-8.

33. Drabo KM, Dauby C, Coste T, Dembelé M, Hien C, Ouedraogo A, et al. Decentralising tuberculosis case management in two districts of Burkina Faso. Int J Tuberc Lung Dis. 2006;10(1):93-8.

34. van der Werf MJ, Langendam MW, Huitric E, Manissero D. Knowledge of tuberculosis-treatment prescription of health workers: a systematic review. Eur Respir J. 2012;39(5):1248-55

35. Khan FA, Minion J, Pai M, Royce S, Burman W, Harries AD, et al Treatment of active tuberculosis in HIV-coinfected patients: a systematic review and meta-analysis. Clin Infect Dis. 2010;50(9):1288-99.

36. Ahuja SD, Ashkin D, Avendano M, Banerjee R, Bauer M, Bayona JN, et al. Multidrug resistant pulmonary tuberculosis treatment regimens and patient outcomes: an individual patient data meta-analysis of 9,153 patients. PLoS Med. 2012;9(8):e1001300

37. World Health Organization. Global Tuberculosis Report 2011 In. Geneva: World Health Organization; 2011.

38. Wood R, Maartens G, Lombard CJ. Risk factors for developing tuberculosis in HIV-1-infected adults from communities with a low or very high incidence of tuberculosis. JAIDS-HAGERSTOWN MD-. 2000:23(1):75-80.

39. Whalen CC, Johnson JL, Okwera A, Hom DL, Huebner R, Mugyenyi P, et al. A trial of three regimens to prevent tuberculosis in Ugandan adults infected with the human immunodeficiency virus. N Engl J Med. 1997;337(12):801-8.

40. Guelar A, Gatell JM, Verdejo J, Podzamczer D, Lozano L, Aznar E, et al. A prospective study of the risk of tuberculosis among HIV-infected patients. Aids. 1993:7(10):1345-50.
41. Menzies D. Canadian Tuberculosis Standards. 7th ed. Ottawa: Public Health Agency of Canada; 2013

42. World Health Organization. Global Tuberculosis Report. Geneva: World Health Organization; 2013.

43. Rieder HL. Epidemiologic basis of tuberculosis control. Paris: International Union Against Tuberculosis and Lung Disease (IUATLD); 1999.

44. Abu-Raddad LJ, Sabatelli L, Achterberg JT, Sugimoto JD, Longini IM, Dye C, et al. Epidemiological benefits of more-effective tuberculosis vaccines, drugs, and diagnostics. Proc Natl Acad Sci U S A. 2009;106(33):13980-5.

45. Borgdorff MW, Floyd K, Broekmans JF. Interventions to reduce tuberculosis mortality and transmission in low-and middle-income countries. Bull World Health Organ. 2002;80(3):217-27.

46. Murray CJ, Salomon JA. Modeling the impact of global tuberculosis control strategies. Proc Natl Acad Sci U S A. 1998;95(23):13881-6.

47. Van Deun A, Maug AKJ, Salim MAH, Das PK, Sarker MR, Daru P, et al. Short, highly effective, and inexpensive standardized treatment of multidrug-resistant tuberculosis. Am J Respir Crit Care Med. 2010;182(5):684-92.

48. Lew W, Pai M, Oxlade O, Martin D, Menzies D. Initial drug resistance and tuberculosis treatment outcomes: systematic review and meta-analysis. Ann Intern Med. 2008;149(2):123-34.

49. Looking beyond 2015- Proposed Global strategy and targets for tuberculosis prevention, care and control after 2015 [http://www.who. int/tb/post2015_strategy/en/]

\section{Submit your next manuscript to BioMed Central and take full advantage of:}

- Convenient online submission

- Thorough peer review

- No space constraints or color figure charges

- Immediate publication on acceptance

- Inclusion in PubMed, CAS, Scopus and Google Scholar

- Research which is freely available for redistribution 